\title{
Neurospora Mutant Exhibiting Hyperproduction of Amylase and Invertase
}

\author{
HOWARD GRATZNER ${ }^{1}$ AND D. N. SHEEHAN ${ }^{2}$ \\ Division of Biology, California Institute of Technology, Pasadena, California 91109, and Department of Zoology, \\ University of South Florida, Tampa, Florida
}

Received for publication 1 November 1968

\begin{abstract}
A mutant strain of Neurospora crassa has been isolated which is derepressed for amylase and $\beta$-fructofuranosidase (invertase). Large amounts of the two enzymes were secreted into the culture medium upon depletion of exogenous carbon source. The resulting increases of the two extracellular enzymes were prevented by actinomycin D, cycloheximide, and glycerol. The starving cells of the mutant strain produced amylase and invertase de novo, as evidenced by incorporation of radioactive amino acids into the enzymes. Preliminary genetic studies indicate that these elevated enzyme levels described are due to a single gene mutation.
\end{abstract}

Wild-type strains of Neurospora crassa grown on maltose or starch secrete $\alpha$-amylase (12) and glucamylase into the growth medium (unpublished data). If the organism is grown on other carbon sources, such as sucrose, only trace amounts of the enzymes are produced.

The purpose of this communication is to report the results of studies comparing the specific activities of amylase of a wild-type strain, 74-OR23$1 \mathrm{~A}$, with the specific activities of a mutant strain, SF26, under conditions of exogenous carbon source depletion. This mutant strain possesses increased endogenous and exogenous levels of amylase, and also of $\beta$-fructofuranosidase (invertase) and trehalase. Evidence will be presented supporting the contention that the increases in amylase and $\beta$-fructofuranosidase activities in strain SF26 result from de novo protein synthesis in the starving cultures.

\section{MATERIALS AND METHODS}

Strains. $N$. crassa wild-type strain 74-OR23-1A was obtained from the Fungal Genetics Stock Center, Dartmouth College. Strain SF 26 was derived in our laboratory from 74A-OR23-1A by ultraviolet irradiation, and was selected by its rapid growth on plates of Vogel's minimal medium (13) plus $2 \%$ agar, $0.5 \%$ starch, and $2 \%$ sorbose. Genetic studies of the mutant strain SF26 will be published in subsequent papers, but in crosses the ability of SF26 to produce high levels of amylase and invertase segregates as a single gene mutation in linkage group I.

1 Present address: Laboratory for Quantitative Biology, Department of Biology, University of Miami, Coral Gables, Fla. 33124.

2 Present address: Biology Division, Oak Ridge National Laboratory, Oak Ridge, Tenn. 37830.
Cultural Conditions. Both the mutant and wild-type strains were maintained on Vogel's minimal medium supplemented with $2 \%$ sucrose.

Still cultures were initiated in 125-ml flasks by inoculating $0.1 \mathrm{ml}$ of a suspension of conidia from 7-day-old cultures into $20 \mathrm{ml}$ of Vogel's medium supplemented with the desired carbohydrates; the cultures were allowed to grow at $30 \mathrm{C}$. The carbohydrate concentration was $0.024 \mathrm{M}$ for mannose and $0.012 \mathrm{M}$ for sucrose and maltose. Concentrations of conidia from both strains were standardized turbidimetrically prior to inoculation into the flasks.

Shakes cultures were grown in Fernbach flasks. A heavy suspension of conidia was inoculated into 2 liters of Vogel's medium supplemented with sucrose $(0.5 \%$, final concentration), and the flasks were shaken on a gyratory shaker at $150 \mathrm{rev} / \mathrm{min}$. Homogeneous samples $(20 \mathrm{ml})$ of the suspended culture were aseptically removed at the desired times with a large widebore pipette.

Preparation of crude extracts and enzyme assays. Mycelia from still cultures and shake cultures were filtered to separate them from the medium, washed in buffer, and then frozen and ground to a fine powder in liquid nitrogen. The powder was suspended in $6 \mathrm{ml}$ of $0.05 \mathrm{M}$ phosphate buffer $(p \mathrm{H} \mathrm{6.0)}$ and centrifuged at $10,000 \times g$ for $15 \mathrm{~min}$ at $4 \mathrm{C}$. The supernatant liquid from this centrifugation was used as the crude extract for enzyme assays and protein determinations (5). The media were saved and assayed for extracellular amylase and invertase activity.

Enzyme assays. Amylase assays were performed according to the method of Bernfeld (1), modified in that the assays were made at $p \mathrm{H} 6.0$ and $37 \mathrm{C}$ for 6 min. Invertase assays were performed on $0.5-\mathrm{ml}$ samples for $6 \mathrm{~min}$ with $0.01 \mathrm{M}$ sucrose in $0.1 \mathrm{M}$ acetate buffer ( $p \mathrm{H} \mathrm{5.3)}$ as the substrate. Reducing sugars were determined with the dinitrosalicylate reagent according to the method of Bernfeld (1). Trehalase was assayed similarly, with $8 \times 10^{-2} \mathrm{M}$ trehalose as sub- 
strate and incubation for $120 \mathrm{~min}$. Specific activities for amylase are expressed as micromoles of maltose liberated per minute per milligram of protein; for invertase, as micromoles of glucose liberated per minute per milligram of protein; and for trehalase, as micromoles of glucose per 120 min per milligram of protein. Alkaline phosphatase was assayed as described by Metzenberg (7). Protein concentrations were determined by the method of Lowry et al. (5). Specific activities of extracellular protein were multiplied by a factor of 3.3 to permit appropriate comparison with specific activities of intracellular protein which were based on the amount of soluble protein in 6-ml samples.

Electrophoresis. Electrophoresis was performed on cellulose acetate strips (Sepraphore III, $17.1 \times 2.5$ cm, Gelman Instrument Co., Ann Arbor, Mich.) as reported previously (2), except that $\beta$-fructofuranosidase was demonstrated directly on the electrophoresis strips. This was done by placing a "reagent strip," previously soaked in an equal mixture of Glucostat reagent ["special" grade (Worthington Biochemical Corp., Freehold, N.J.), saturated with $o$ tolidine (3)] and $10^{-2} \mathrm{M}$ buffered sucrose solution, directly on the electrophorsis strip subsequent to electrophoresis. The presence of a brownish-purple band was indicative of $\beta$-fructofuranosidase activity. Amylases were demonstrated as previously described (2). In most of the experiments reported herein, the growth medium from strain SF26 cultures was applied directly to the electrophoresis strips in 10- $\mu$ liter amounts prior to electrophoresis.

Antibiotic inhibition experiments. Actinomycin D was a gift from Merck, Sharp and Dohme Research Laboratories, West Point, $\mathrm{Pa}$.; the cycloheximide was a product of The Upjohn Co., Kalamazoo, Mich. Both compounds were used at final concentrations of $4 \mu \mathrm{g} / \mathrm{ml}$ in the growth medium. The drugs were added to still cultures after $40 \mathrm{hr}$ of growth, and the $125-\mathrm{ml}$ flasks were then shaken at $30 \mathrm{C}$ for the desired time intervals, at which time the assays were made as described above.

Amino acid incorporation experiments. For studies of ${ }^{14} \mathrm{C}$-amino acid incorporation into amylase, the. enzyme was concentrated from the culture medium by coprecipitation with glycogen, by use of a modification of the technique of Loyter and Schramm (6).

To each of a series of 125 -ml flasks containing mycelial pads was added $2 \mu \mathrm{c}$ of reconstituted ${ }^{14} \mathrm{C}$-algal hydrolysate (New England Nuclear Corp., Boston, Mass.), and the flasks were shaken at $25 \mathrm{C}$ for the indicated time interval. At the desired times, a 5-ml sample of the medium was made to a final concentration of $40 \%$ ethyl alcohol and centrifuged at $8,000 \times$ $g$ for $10 \mathrm{~min}$. The precipitate was discarded, and 4.5 $\mathrm{ml}$ of the supernatant liquid was placed into a fresh centrifuge tube in an ice bath; $400 \mu \mathrm{g}$ of unlabeled carrier Neurospora amylase was added to each tube. The enzyme was adsorbed and precipitated by the addition of $0.2 \mathrm{ml}$ of a $2 \%$ glycogen solution. The tubes were allowed to stand for $5 \mathrm{~min}$ in the ice bath. They were then centrifuged for $10 \mathrm{~min}$ at $10,000 \times g$; the supernatant liquid was discarded, and the pellet was washed twice in the centrifuge with ice cold $40 \%$ ethyl alcohol. The washed pellet was dissolved in 0.05 M phosphate buffer ( $p H$ 6.0) and permitted to stand at room temperature for $30 \mathrm{~min}$. A slight precipitate that formed during this period was removed by an additional centrifugation at $10,000 \times g$ for $15 \mathrm{~min}$. A $0.5-\mathrm{ml}$ sample from each tube was added to a $15-\mathrm{ml}$ dioxane-based scintillation fluid in a counting vial, and was counted in a Packard Tri-Carb liquid scintillation spectrometer.

Cellulose acetate electrophoresis strips were sequentially analyzed for radioactivity by placing $2-\mathrm{mm}$ strips cut laterally from each electrophoresis strip into scintillation vials, with a dioxane-based scintillation fluid.

\section{RESULTS}

Comparison of specific activities in still culture. In Table 1 are tabulated the relative values for specific activities of the mutant strain SF26 and wild-type 74-OR23-1A. Although there are large variations between the two experiments, it is clear that the amylase and $\beta$-fructofuranosidase activities were higher in the mutant strain under all conditions of growth tested. In fact, the activity of strain SF26 grown on sucrose was even higher than that found for 74-OR23-1A grown on maltose, a sugar which appears to induce amylase in this wild-type strain. It is also to be noted that strain SF26 was induced by maltose to a level which was substantially higher than when the strain was grown on glucose or mannose. A further observation is that some component of dextrin was more effective than maltose in inducing amylase in Neurospora.

Time-course studies in shaken culture. When strain SF26 was grown on limiting sucrose, and the specific activity of amylase was followed over a period of time, it was found that the activity was negligible in the culture until that time when the carbon source was depleted from the medium. Figure 1 shows that a sharp increase in amylase occurred at approximately $36 \mathrm{hr}$ after inoculation of the culture, at a time when the carbon source, as measured by reducing sugars, became depleted. Concurrent with this carbon source depletion, growth, as measured by dry weight, ceased. Thus, it appears that amylytic activity was increasing in the culture after cessation of growth and at the onset of "starvation."

In Fig. 2, the total specific activities of amylase, $\beta$-fructofuranosidase, and a third hydrolase, trehalase, are plotted versus time for strains 74OR23-1A and SF26. The data were derived from experiments in which suspended shake cultures in Fernbach flasks were grown on limiting sucrose.

It can be seen from Fig. 2 that the activities of at least three enzymes were highly elevated in strain SF26 when compared with 74-OR23-1A.

To establish whether the increases in these three 
TABLE 1. Specific activities of amylase and $\beta$-fructofuranosidase

\begin{tabular}{|c|c|c|c|c|c|c|c|c|}
\hline \multirow{2}{*}{ Strain } & \multirow{2}{*}{ Expt } & \multirow{2}{*}{ Carbon source } & \multicolumn{3}{|c|}{ Amylase } & \multicolumn{3}{|c|}{$\beta$-Fructofuranosidase } \\
\hline & & & Extracellular & Intracellular & Total & Extracellular & Intracellular & Total \\
\hline SF26 & $\begin{array}{l}1 \\
2 \\
1 \\
2 \\
1 \\
2 \\
2\end{array}$ & $\begin{array}{l}\text { Sucrose } \\
\text { Maltose } \\
\text { Mannose } \\
\text { "Dextrin" }\end{array}$ & $\begin{array}{r}3.5 \\
3.0 \\
22.0 \\
8.5 \\
2.7 \\
2.7 \\
8.0\end{array}$ & $\begin{array}{l}0.4 \\
0.3 \\
0.4 \\
0.6 \\
1.8 \\
0.7 \\
1.0\end{array}$ & $\begin{array}{r}3.9 \\
3.3 \\
22.4 \\
9.1 \\
4.5 \\
3.4 \\
9.0\end{array}$ & $\begin{array}{r}6.0 \\
2.1 \\
16.3 \\
3.5 \\
6.3 \\
3.3 \\
0.4\end{array}$ & $\begin{array}{l}4.3 \\
3.3 \\
9.4 \\
3.8 \\
4.6 \\
3.7 \\
8.6\end{array}$ & $\begin{array}{r}10.3 \\
5.4 \\
25.7 \\
7.3 \\
10.9 \\
7.0 \\
9.0\end{array}$ \\
\hline 740R231A & $\begin{array}{l}1 \\
2 \\
1 \\
2 \\
1 \\
2 \\
2\end{array}$ & $\begin{array}{l}\text { Sucrose } \\
\text { Maltose } \\
\text { Mannose } \\
\text { "Dextrin" }\end{array}$ & $\begin{array}{l}0.2 \\
0.06 \\
2.4 \\
0.7 \\
0.2 \\
0.2 \\
1.5\end{array}$ & $\begin{array}{l}0.2 \\
0.07 \\
0.2 \\
0.2 \\
0.1 \\
0.2 \\
0.2^{2}\end{array}$ & $\begin{array}{l}0.4 \\
0.13 \\
2.6 \\
0.9 \\
0.3 \\
0.4 \\
1.8\end{array}$ & $\begin{array}{l}1.9 \\
0.2 \\
1.3 \\
0.5 \\
0.4 \\
0.1 \\
0.5\end{array}$ & $\begin{array}{l}1.9 \\
1.0 \\
2.5 \\
1.6 \\
0.8 \\
0.7 \\
1.7\end{array}$ & $\begin{array}{l}3.8 \\
1.2 \\
3.8 \\
2.1 \\
1.2 \\
0.8 \\
2.2\end{array}$ \\
\hline
\end{tabular}

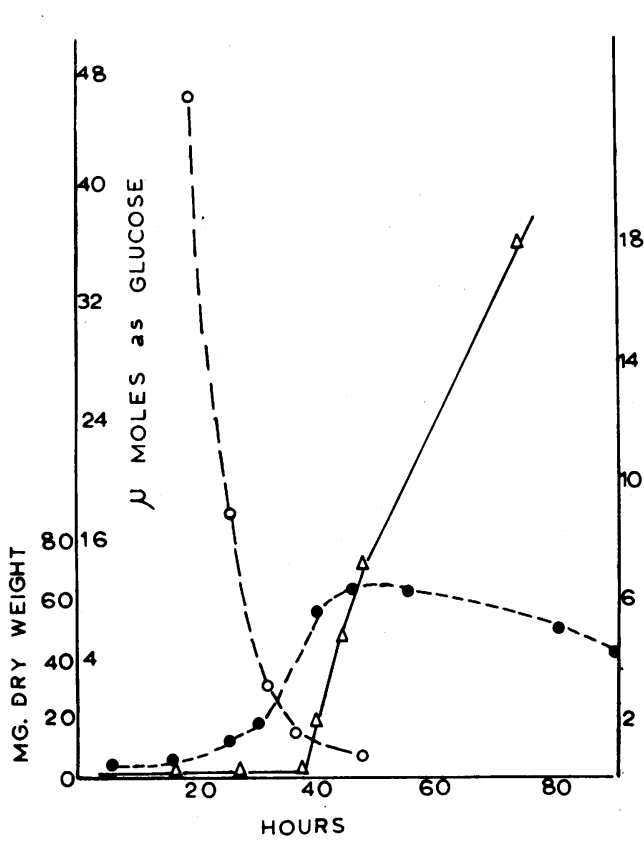

FIG. 1. Changes in dry weight, extracellular reducing sugars, and amylase activity during the growth of strain SF26 in still culture. Symbols: 0 , dry weight; $O$, reducing sugars; $\Delta$, amylase, specific activity (units per milligram of dry weight).

hydrolases are but a manifestation of a general increase in enzymatic activity, a fourth enzyme, alkaline phosphatase, was assayed concurrently. No differences were observed in the alkaline phosphatase activities in the two strains, SF26 and 74-OR23-1A.

Since molecular sieving of $\beta$-fructofuranosidase

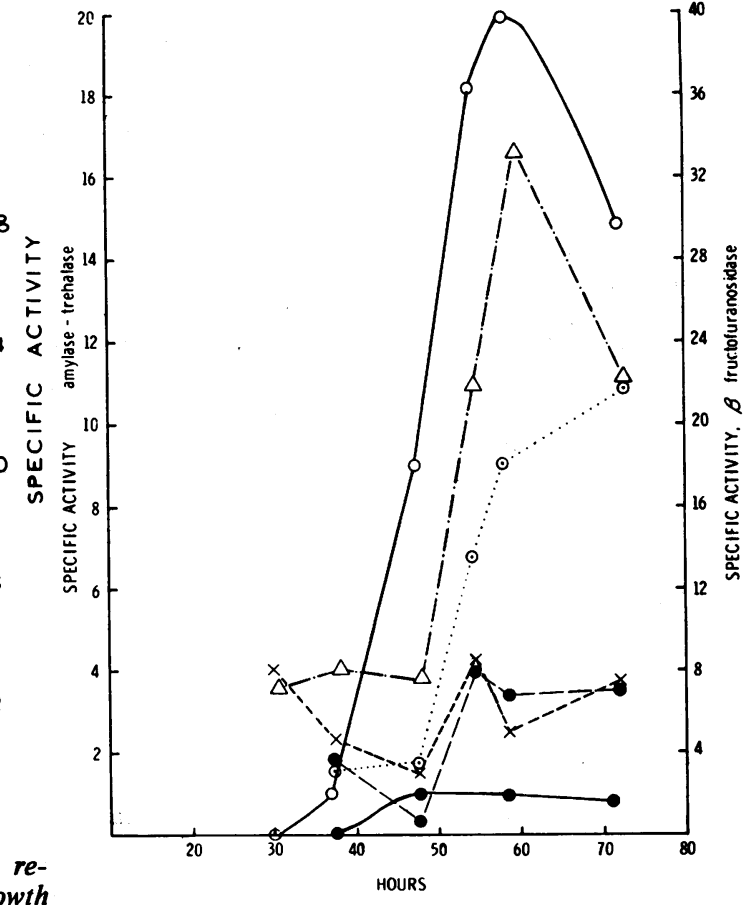

Fig. 2. Comparison of total (intracellular and extracellular) specific activities of amylase, $\beta$-fructofuranosidase, and trehalase in strains 74-OR23-1A and SF26. Symbols: O, amylase, SF26; $\Delta$, $\beta$-fructofuranosidase, SF26; $\odot$, trehalase, SF26; $-O$, amylase, 74-OR23-1A; - $\beta$-fructofuranosidase, 74-OR23-1A; $\times$, trehalase, 74-OR23-1A.

has been reported to occur through cell walls in Neurospora (11), it was of interest to determine whether any differences could be detected in the 
intracellular and extracellular levels of these enzymes in the two strains. Figure 3 depicts an experiment in which the ratios of extracellular and intracellular $\beta$-fructofuranosidase in both wild and mutant strains were examined. The relative distributions of $\beta$-fructofuranosidase were approximately the same in both strains.

Segregation of mutation in strain SF26. The genetics of strain SF26 will be described in more detail elsewhere, but the aberration exhibited by strain SF26 segregates as a single gene, as determined by assays of cultures derived from spores dissected from asci representing single meiotic events and also from random spores. Of 92 random spores assayed for amylase and $\beta$-fructofuranosidase, 42 had the SF26 phenotype (high amylase, high $\beta$-fructofuranosidase) and 49 had wild-type enzyme activities. Table 2 gives specific activities of amylase and $\beta$-fructofuranosidase from a dissected ascus. From these data, it appears that the increased levels of both enzymes are the result of the same, or closely linked, loci.

De novo synthesis of amylase and $\beta$-fructofuranosidase. The effects of cycloheximide, actinomycin $\mathrm{D}$, and glycerol on starving cultures of strain SF26 are summarized in Table 3. In these experiments, the antibiotic or glycerol was added to cultures which had grown into a mycelial mat

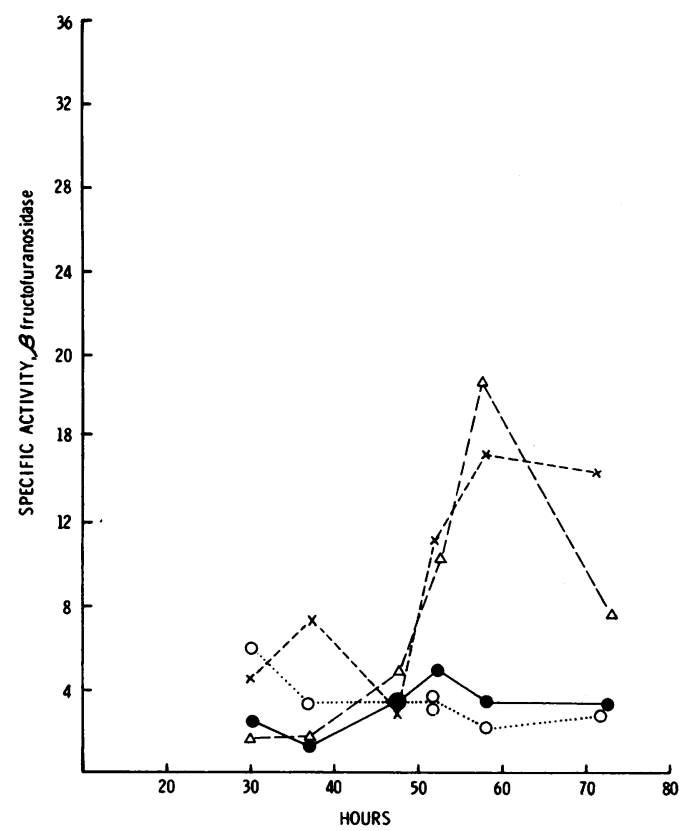

Fig. 3. Comparison of extracellular and intracellular specific activities of $\beta$-fructofuranosidase in wild type (74-OR23-1A) and strain SF26. Symbols: $\triangle$, extracellular, SF26; $\times$, intracellular, SF 26; extracellular, 74-OR23-1A; O, intracellular, 74OR23-1A.
TARLE. 2. Specific activities of cultures derived from single-ordered ascus

\begin{tabular}{c|c|c}
\hline Spore & Glucose & Invertase \\
\hline 1 & 0.018 & 0.108 \\
2 & 0.011 & 0.127 \\
3 & 0.049 & 0.167 \\
4 & - & - \\
5 & 0.410 & 0.253 \\
6 & 0.343 & 0.191 \\
7 & 0.440 & 0.390 \\
8 & 0.505 & 0.396 \\
\hline
\end{tabular}

TABLE 3. Inhibition of amylase and $\beta$-fructofuranosidase by antibiotics and exogenous carbon source in SF26a

\begin{tabular}{c|c|c}
\hline \multirow{2}{*}{ Inhibitor } & \multicolumn{2}{|c}{ Inhibition (\%) } \\
\cline { 2 - 3 } & Amylase & $\begin{array}{c}\beta \text {-Fructo- } \\
\text { furanosidase }\end{array}$ \\
\hline Cycloheximide $(4 \mu \mathrm{g} \mathrm{ml}) \ldots$ & 91 & 96 \\
Actinomycin D $(4 \mu \mathrm{g} \mathrm{ml}) .$. & 71 & 75 \\
Glycerol $(0.012 \mathrm{M}) \ldots \ldots \ldots$. & 77 & 80 \\
\hline
\end{tabular}

a Antibiotics or glycerol was added at $40 \mathrm{hr}$; cultures were shaken for an additional $20 \mathrm{hr}$ at $25 \mathrm{C}$ and were assayed as described in Materials and Methods.

in still culture. The cultures were assayed $20 \mathrm{hr}$ after addition of antibiotic or glycerol. Amylase and $\beta$-fructofuranosidase were inhibited to a similar extent by the treatment.

Amino acid incorporation studies. As an additional test of the concept that the enzymes are produced de novo in starving cultures of strain SF26, the incorporation of ${ }^{14} \mathrm{C}$-amino acids into the extracellular amylase was followed. As is shown in Fig. 4, the radioactivity in the glycogen fraction increased with time, as would be expected if the enzyme were produced de novo in the cultures. The presence of cycloheximide $(4 \mu \mathrm{g} / \mathrm{ml})$ prevented the increases manifested by the control flasks. That the label from the amino acids was incorporated into amylase protein was demonstrated by the fact that almost all of the label resided in peaks corresponding to bands of glucamylase activity (Fig. 5). A small amount of invertase was apparently carried down with the glycogen precipitate. This was also radioactive, showing that amylase and invertase are made de novo under the conditions of carbon source deprivation in the experiments described.

\section{DISCUSSION}

A mutant of Neurospora has been described in which at least three enzymes of carbohydrate 


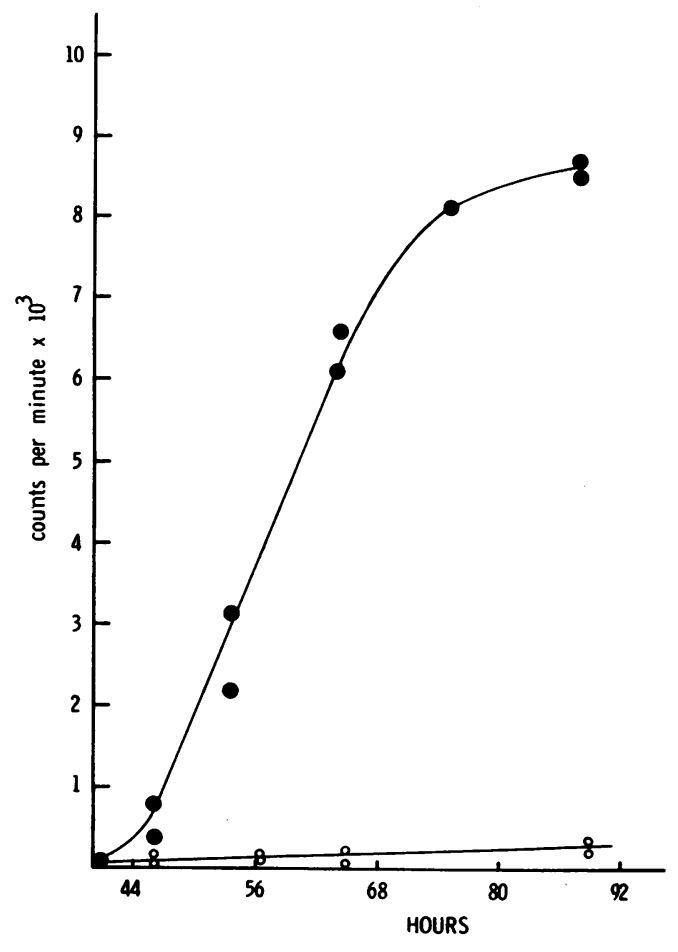

FIG. 4. Incorporation of ${ }^{14} \mathrm{C}$-amino acids into amylase, and effect of cycloheximide on incorporation. Symbols: O, control; O, 4 ug of cycloheximide per ml.

catabolism are produced in elevated amounts. The enzymes studied were $\beta$-fructofuranosidase, trehalase, and amylase. We have found that over $90 \%$ of the amylase activity is due to glucamylase (9), an enzyme which hydrolyzes $\alpha 1-4$ glucosidic bonds to yield glucose as the hydrolysis product (in preparation). Another enzyme, alkaline phosphatase, does not exhibit increased activity in the mutant strain. The high activities of two of the three enzymes are associated with what appears to be a single gene mutation, their elevated activities segregating together in crosses.

Metzenberg (7) reported the isolation of a mutant of Neurospora which is coordinately derepressed for invertase and trehalase in mycelia. However, Hill and Sussman (3) showed that the two activities were not coordinate in other stages of the life cycle. Thus, our studies, while possibly indicating some type of regulatory relationship in mycelia, are not complete over the entire life cycle. Horowitz (4) found that two metabolically unrelated enzymes, tyrosinase and L-amino acid oxidase, are simultaneously produced by starving cultures, or cultures induced by amino acid analogues.

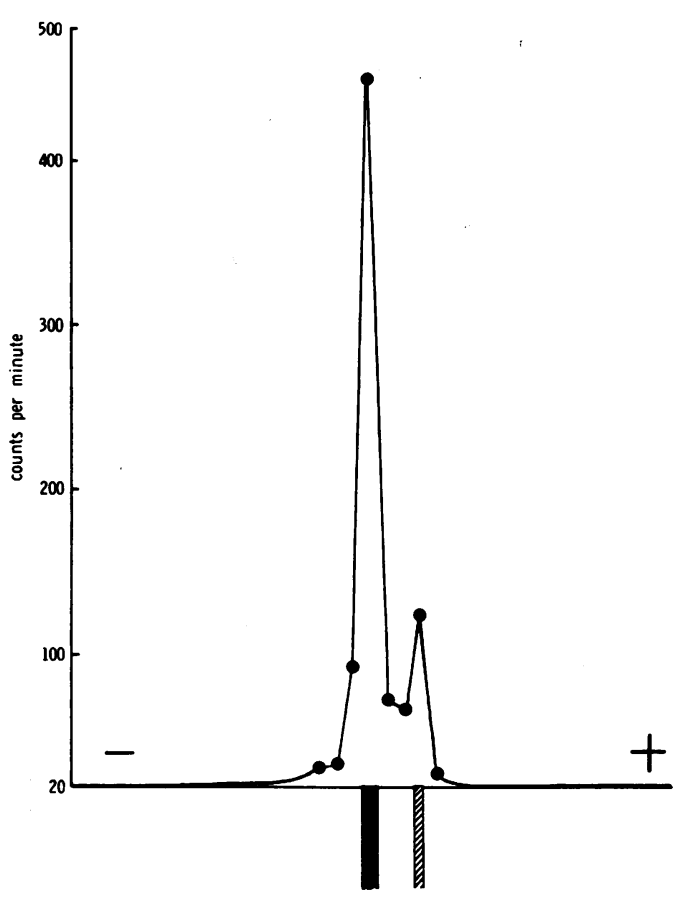

FIG. 5. Electrophoresis of radioactive amylase and $\beta$-fructofuranosidase purified by glycogen coprecipitation from growth media. The bands at the bottom of the curve represent the electrophoresis strips sectioned and counted. (Staining was with amidoschwarz.)

Comparative studies of extracellular and intracellular enzyme activities for amylase and invertase support the notion that strain SF26 contains a mutation causing hyperproduction of enzymes and is not merely a mutant which more readily permits the passage of the enzymes through the cell wall.

Trevithick and Metzenberg have postulated that a molecular sieving process accounts for extracellular invertase secretion $(10,11)$. It is interesting in this regard that amylase is found predominantly in the medium (predicated upon the supposition that little inactive amylase proenzyme is present intracellularly), whereas the invertase is distributed between the cells and the medium almost equally. At present, we do not know the molecular size of the amylases in $\mathrm{Neu}$ rospora, nor do we know whether they have ability to aggregate into dimers, as has been shown by Metzenberg to occur with invertase (8).

\section{ACKNO WLEDGMENTS}

This investigation was supported by National Science Foundation grant GB-4537 and by a special Public Health Service fellowship, 1F3-CA-25,17301.

We are grateful for the very able assistance of Stephen Bloom. 


\section{LITERATURE GITED}

1. Bernfeld, P. 1955. Amylases, p. 149-158. In S. P. Colowick and N. O. Kaplan (ed.), Methods in enzymology, vol. 1. Academic Press, Inc., New York.

2. Gratzner, H. G. 1966. A convenient method for the electrophoresis of amylase and invertase on cellulose acetate strips. Neurospora Newsletter 9:9.

3. Hill, E. P., and A. S. Sussman. 1964. Development of trehalase and invertase activity in Neurospora. J. Bacteriol. 88:15561566.

4. Horowitz, N. H. 1965. Evidence for the common control of tyrosinase and $\mathrm{L}$-amino acid oxidase in Neurospora. Biochem. Biophys. Res. Commun. 18:686-692.

5. Lowry, O. H., N. J. Rosebrough, A. L. Farr, and R. J. Randall. 1951. Protein measurement with the Folin phenol reagent. J. Biol. Chem. 193:265-275.

6. Loyter, A. and M. Schramm. 1962. The glycogen-amylase complex as a means of obtaining highly purified $\alpha$-amylases. Biochim. Biophys. Acta 65:200-206.

7. Metzenberg, R. L. 1962. A gene affecting the repression of invertase and trehalase in Neurospora. Arch. Biochem. Biophys. 96:468-474.

8. Metzenberg, R. L. 1963. Purification and properties of invertase of Neurospora. Arch. Biochem. Biophys. 100:503511.

9. Phillips, L. L., and M. L. Caldwell. 1951. A study of the purification and properties of a glucose-forming amylase from Rhizopus delemar, glucamylase. J. Am. Chem. Soc. 73:35593563.

10. Trevithick, J. R., and R. L. Metzenberg. 1964. Secretion of invertase by Neurospora protoplasts. Biochem. Biophys. Res. Commun. 17:319-352.

11. Trevithick, J. R., and R. L. Metzenberg. 1966. Molecular sieving by Neurospora cell walls during secretion of invertase isozymes. J. Bacteriol. 92:1010-1015.

12. Tsujisaka, Y. and J. Fukarnato. 1960. Studies of fungal hydrolases. Sci. Ind. (Osaka) 34:198-201.

13. Vogel, H. J. 1964. Distribution of lysine pathways among fungi: evolutionary implications. Am. Naturalist 98:435446. 